cation for veneer timber breeding of new triploid clones in Populus tomentosa Carr.. Forestry Studies in China, 4: $52-60$.

Xu, W. Y. (1988): Poplar, Helongjiang People Press, Harbin, Heilongjian Province, China, pp 297.

Xu, D. P., Q. Z. Xue, D. McElroy, Y. MaWal, V. A. Hilder and R. WU (1996): Constitutive expression of a cowpea trypsin inhibitor gene, $C p T I$, in transgenic rice plants confers resistance to two major rice insect pests. Molecular Breeding. 2: 167-173.

YANG, M. S., H. Y. LANG, G. J. GAO, J. M. WANG and J. B. ZHENG (2003): Insecticidal activity and transgene expression stability of transgenic hybrid poplar clone 741 carrying two insect-resistant genes. Silvae Genetica. 52: 5-6.
Zhang, Z. Y., F. L. Li and Z. T. ZHU (1992): Chromosome doubling and triploid breeding of Populus tomentosa Carr. and its hybrid. J. Beijing For. Uni. 14(supp): $52-58$.

ZHANG, Z. Y., F. L. Li and Z. T. ZHU (1997b): Doubling technology of pollen chromosome of Populus tomentosa and its hybrids, J. Beijing For. Uni. (English Ed.) 6: 9-20.

Zhang, Z. Y., X. S. YU and Z. T. ZHU (2000): Sexual reproduction of hybrid triploids in Populus tomentosa. J. Beijing For. Uni. 22: 1-4.

Zhang, Z. Z. (1997a): Forest Entomology. China Forestry Publishing House. Beijing, pp 221.

ZHU, Z. T. and Z. Y. ZHANG (1997): Status and advances of genetic improvement of Populus tomentosa Carr.. J. Beijing For. Uni. (English Ed.) 6: 1-7.

\title{
Population Genetic Survey of Populus cathayana Originating From Southeastern Qinghai-Tibetan Plateau of China Based on SSR Markers
}

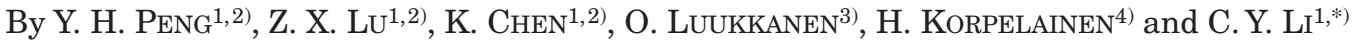

(Received 1 ${ }^{\text {st }}$ April 2005)

\begin{abstract}
In this study, the genetic diversity of Populus cathayana Rehd was investigated using microsatellite markers. In a total of 150 individuals collected from six natural populations in the southeastern part of the Qinghai-Tibetan Plateau in China, a high level of microsatellite polymorphism was detected. At the seven investigated microsatellite loci, the number of alleles per locus ranged from 5 to 16 , with a mean of 11.3 , the observed heterozygosities across populations ranged from 0.408 to 0.986 , with a mean of 0.792 , and the expected heterozygosities across populations ranged from 0.511 to 0.891 , with a mean of 0.802 . The proportion of genetic differentiation among populations accounted for $37.3 \%$ of the whole genetic diversity. The presence of such a high level of genetic diversity could be attributed to the features of the species and the habitats where the sampled populations occur: The southeastern part of the Qinghai-Tibetan Plateau is regarded as the natural distribution and variation center of the genus Populus in China. Variation in environmental

1) Chengdu Institute of Biology, Chinese Academy of Sciences, P.O. Box 416, Chengdu 610041, P. R. China.

2) Graduate School of the Chinese Academy of Sciences, Beijing 100039, P. R. China.

3) Viikki Tropical Resources Institute, P.O.Box 28, FI-00014 University of Helsinki, Finland.

4) Department of Applied Biology, P.O. Box 27, FI-00014 University of Helsinki, Finland.

*) Correspondence address: ChunYang Li, Chengdu Institute of Biology, Chinese Academy of Sciences, P.O. Box 416, Chengdu 610041, P. R. China, Tel: +86-28-85221347, Fax: +8628-85222753, Email: licy@cib.ac.cn, chunyang.li@helsinki.fi
\end{abstract}

conditions and selection pressures in different populations, and topographic dispersal barriers could be factors associated with the high level of genetic differentiation found among populations. The populations possessed significant heterozygosity excesses, which may be due to extensive population mixing at the local scale. The cluster analysis showed that the populations are not strictly grouped according to their geographic distances but the habitat characteristics also influence the divergence pattern. In addition, we suggest that population SHY should be regarded as an ecologically divergent species of $P$. cathayana.

Key words: Genetic differentiation, Genetic diversity, Heterozygosity excess, Microsatellites, Populus cathayana.

\section{Introduction}

The Qinghai-Tibetan Plateau is the largest and highest plateau of the world, located in southwestern China. Due to its unique geographical and geological historical factors, variable terrain and complex climatic conditions, the Qinghai-Tibetan Plateau, especially its southern and eastern mountain areas, has abundant and special resources of the genus Populus, and it is regarded as the natural distribution and variation center of genus Populus in China (Weisgerber and Han, 2001; YU, 2003). Many Populus species, mainly of Sect. Tacamahaca Spach, occur in the mountains and canyon belts between the plateau and plain at altitudes varying between 1,500-4,300 $\mathrm{m}$ above sea level. Most native species of this section have strong resistance against stressful environments, and they are used as important genetic resources for plantation and breeding work in 
Populus. On the other hand, because a number of foreign species have been introduced to China and planted extensively during recent decades, the native species face a serious decline in their distribution areas and a risk of genetic resources becoming poor and narrow.

$P$. cathayana Rehd is a native species of China and it belongs to Sect. Tacamahaca Spach. It mainly occurs in the northern, southwestern and central parts of China and possesses a large geographic range. The different habitats, complex climatic conditions and variable selection pressures may have led to considerable genetic differentiation. Taxonomical, morphological and physiological studies on $P$. cathayana have been conducted (YANG et al., 1996; Su et al., 1998; GAO et al., 2004). However, very little information is available on the genetic diversity of this species based on molecular marker techniques.

Microsatellite markers, or simple sequence repeats (SSRs) (BECKMANN and Soller, 1990; SMITH and DEvEY, 1994; ECHT et al., 1996), derived from the non-coding region of the genome, are co-dominant markers. They have contributed considerably towards the knowledge of the genome structure, function and evolution in forest trees (AHUJA, 2001). Recently, several microsatellite markers have been developed for the genus Populus (DAYAMANDAN et al., 1998; RAHMAN et al., 2000; VAN DER Schoot et al., 2000; SMULders et al., 2001), and they have been applied to studies on individual identification, genetic linkage map construction, genetic diversity of natural or breeding populations, gene flow, pollen or seed dispersal and mating systems (RAHMAN and RAJORA, 2002; IMBERT and LEFÈVRE, 2003; RAJORA and RAHMAN, 2003; TABBENER and CotTRELL, 2003). Reliable information on the distribution of genetic variation is a prerequisite for sound selection, breeding and conservation programs in forest trees, such as $P$. cathayana.

In the present study, seven primer pairs were used to investigate the level and distribution of genetic diversity in six populations of $P$. cathayana originating from their natural range in southwestern China. This work provides a deep insight into the genetic variability and population genetic structure of $P$. cathayana, and it also produces valuable informations for further conservation and breeding programs in $P$. cathayana.

\section{Materials and Methods}

\subsection{Plant materials}

A total of 150 individuals from six natural populations of $P$. cathayana were collected from the southern and

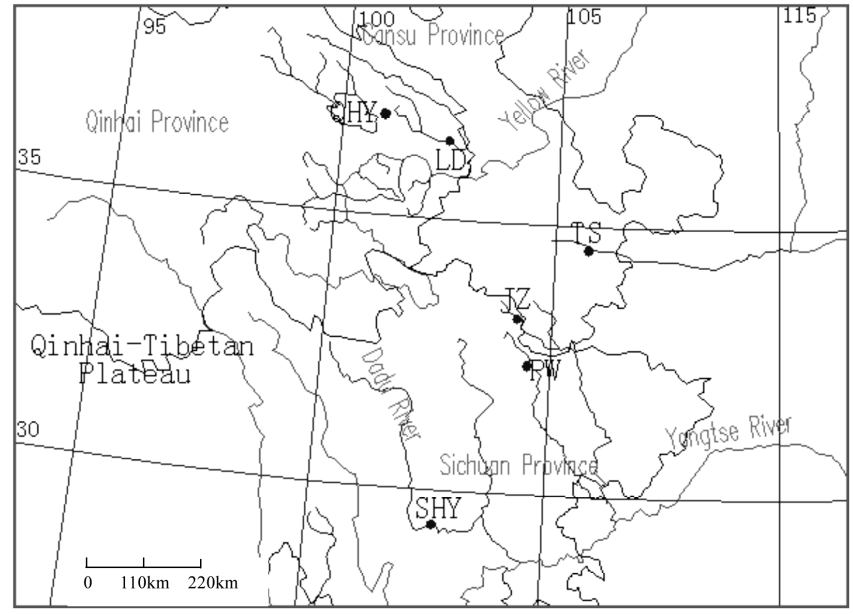

Figure 1. - The geographical distribution of P. cathayana in China. The locations of the natural populations sampled in this study are shown. Population abbreviations are given in Table 1.

eastern parts of the Qinghai-Tibetan Plateau. The six sampled populations, three populations (SHY, JZ, PW) from the Sichuan province, two populations (QHY, LD) from the Qinghai province and one (TS) from the Gansu province, represent the major areas of natural resources for P. cathayana in China (Fig. 1). The locations of the populations, and the ecological and geographical parameters are shown in Table 1. For each population, individual cuttings, separated by a distance of more than 50 $\mathrm{m}$ in order to retain individual independence, were sampled during winter 2003, and all collected cuttings were transferred and planted in a stool bed at the Maoxian Field Ecological Station.

\subsection{DNA extraction}

Current-year leaves were collected, and DNA was extracted using $0.5 \mathrm{~g}$ of leaf material from each individual following the procedure described by CASTIGLIONE $e t$ al. (1993). Approximate DNA concentrations were estimated on agarose gels using a DNA standard and ethidium bromide staining (MANIATIS et al., 1982). The total DNA was diluted to a concentration of about $20 \mathrm{ng}^{-1}$ with the buffer TE (Tris- $\mathrm{HCl} \mathrm{pH} 8.0$ and $0.1 \mathrm{mM}$ EDTA $\mathrm{pH}$ 8.0).

\subsection{PCR amplification and electrophoresis}

Fourteen WPMS SSR primer pairs (WPMS03, WPMS04, WPMS05, WPMS06, WPMS07 WPMS08, WPMS09, WPMS10, WPMS12, WPMS14, WPMS15,

Table 1. - The ecological and geographical parameters of $P$. cathayana populations sampled.

\begin{tabular}{|c|c|c|c|c|c|c|c|c|}
\hline Population & Landform feature & Water system & $\begin{array}{l}\text { Sample } \\
\text { size }\end{array}$ & $\begin{array}{l}\text { Longitude } \\
\text { (E) }\end{array}$ & $\begin{array}{l}\text { Latitude } \\
\text { (N) }\end{array}$ & $\begin{array}{l}\text { Altitude } \\
\text { (m) }\end{array}$ & $\begin{array}{l}\text { Annual } \\
\text { rainfall } \\
(\mathrm{mm})\end{array}$ & $\begin{array}{l}\text { Annual mean } \\
\text { temperature } \\
\left({ }^{\circ} \mathrm{C}\right)\end{array}$ \\
\hline SHY & Riparian and basin & Dadu river & 30 & $102^{\circ} 40^{\prime}$ & $29^{\circ} 25^{\prime}$ & 1500 & 750 & 17.7 \\
\hline $\mathrm{JZ}$ & Alpine and canyon & Bailong river & 21 & $103^{\circ} 57^{\prime}$ & $32^{\circ} 13^{\prime}$ & 1600 & 553 & 12.7 \\
\hline PW & Canyon and basin & Peijing river & 20 & $104^{\circ} 25^{\prime}$ & $32^{\circ} 01^{\prime}$ & 1620 & 566 & 14.7 \\
\hline QHY & Plateau and mountain & Huangshui river & 30 & $100^{\circ} 23^{\prime}$ & $37^{\circ} 54^{\prime}$ & 3100 & 412 & 3.3 \\
\hline LD & Plateau and mountain & Huangshui river & 30 & $102^{\circ} 28^{\prime}$ & $36^{\circ} 31^{\prime}$ & 3160 & 335 & 6.9 \\
\hline TS & Canyon and basin & Wei river & 19 & $105^{\circ} 40^{\prime}$ & $34^{\circ} 37^{\prime}$ & 1650 & 531 & 11.5 \\
\hline
\end{tabular}


WPMS16, WPMS18 and WPMS20), previously developed for genetic studies in different Populus species (VAN DER SCHOOT et al., 2000; SMULDERS et al., 2001), were first tested. Seven primer pairs (WPMS03, WPMS05, WPMS07, WPMS10, WPMS12, WPMS14 and WPMS18) were found to produce clear, easily scorable DNA bands, and they were used for all further experiments. The PCR reactions were based on the protocols developed by VAN DER SCHOOT et al. (2000) and SMULDERS et al. (2001). Amplification reactions were performed in a volume of $25 \mu \mathrm{l}$ containing reaction buffer, $150 \mu \mathrm{M}$ of dNTP (Promega USA), $0.4 \mu \mathrm{M}$ of each primer, $1.5 \mathrm{U}$ of Taq polymerase (TaKaRa), 20-40 ng of genomic DNA. Two different thermal profiles were used in PCR. The first program, named Normal Program (NP), included the following steps: $94^{\circ} \mathrm{C}$ for $3 \mathrm{~min}, 1$ cycle; $94^{\circ} \mathrm{C}$ for $5 \mathrm{~s}$, the annealing temperature (the annealing temperatures for each specific primer pairs are given in Table 2) for $15 \mathrm{~s}, 72{ }^{\circ} \mathrm{C}$ for $60 \mathrm{~s}, 35$ cycles; $72{ }^{\circ} \mathrm{C}$ for $10 \mathrm{~min}, 1$ cycle. The second program, named Long Program (LP), was as follows: $94^{\circ} \mathrm{C}$ for $3 \mathrm{~min}, 1$ cycle; $94^{\circ} \mathrm{C}$ for $45 \mathrm{~s}$, the annealing temperature for $45 \mathrm{~s}, 72^{\circ} \mathrm{C}$ for $105 \mathrm{~s}, 35$ cycles; $72{ }^{\circ} \mathrm{C}$ for $10 \mathrm{~min}, 1$ cycle. The amplified PCR products were separated on $8 \% \mathrm{w} / \mathrm{v}$ non-denaturing polyacrylamide gels. The electrophoresed gels were silver-stained to visualize the DNA bands. In all cases, PCR reactions were performed at least twice in order to ensure that the absence of any DNA bands was real and not a failed reaction.

\subsection{Statistical analysis}

The DNA fragments amplified by microsatellite primers were scored as alleles on the basis of size comparison with external standards using the Gel Doc $1000^{\mathrm{TM}}$ image analysis system (Biorad USA). The data were entered in the form of single-individual genotypes, following the specifications of the population genetic software package POPGENE, program version 1.32. Standard population genetic parameters were assessed in terms of observed number of alleles per locus $\left(N_{\mathrm{a}}\right)$, mean number of alleles per locus, effective number of alleles per locus $\left(N_{\mathrm{e}}\right)$, observed heterozygosity $\left(H_{\mathrm{o}}\right)$ and expected heterozygosity $\left(H_{\mathrm{e}}\right)$. Departures from the Hardy-Weinberg (H-W) equilibrium were assessed for each locus in each population, and per locus across all populations using the $F$-statistics of WRIGHT (1978). The significance of the deviation was evaluated with a chisquare test, as described by Workman and Niswander (1970).

The genetic structures were further investigated using NEI's (1978) analysis. The proportion of the total genetic differentiation found among populations $\left(G_{\mathrm{ST}}\right)$ was calculated from $G_{\mathrm{ST}}=D_{\mathrm{ST}} / H_{\mathrm{T}}$. Gene flow $(N \mathrm{~m})$ was estimated from $N \mathrm{~m}=0.25\left(1-F_{\mathrm{ST}}\right) / F_{\mathrm{ST}}$. NEI's (1978) unbiased genetic distances were calculated for all population pairs and used to construct a phylogenetic tree (UPGMA), and the bootstrap support values for the phylogenetic tree were computed by PHYLIP 3.6 (FELSENSTEIN, 2004).

\section{Results}

\subsection{Microsatellite DNA polymorphism}

The loci WPMS03, WPMS05, WPMS07, WPMS10 and WPMS 12 contained dinucleotide repeats while the loci WPMS14 and WPMS18 were composed of trinucleotide repeats. All seven assayed loci expressed simple-locus patterns and they were all polymorphic in $P$. cathayana. A summary of the loci and genetic diversity parameters are given in Table 2. A total of 79 alleles were identified in the six $P$. cathayana populations, with the number of alleles per locus ranging from 5 at WPMS18 to 16 at WPMS05. The mean number of alleles across all loci equaled 11.3, and the mean effective number of alleles

Table 2. - Characterization of the seven polymorphic microsatellite markers in P. cathayana.

\begin{tabular}{|c|c|c|c|c|c|c|c|}
\hline $\begin{array}{l}\text { Microsatellite } \\
\text { locus }\end{array}$ & Primer sequences $\left(5^{\prime}-3^{\prime}\right)$ & Repeat type & $\begin{array}{l}\text { Amplification } \\
\text { conditions }\end{array}$ & $N_{\mathrm{a}}$ & $N_{\mathrm{e}}$ & $H_{\mathrm{o}}$ & $H_{\mathrm{e}}$ \\
\hline WPMS03 & $\begin{array}{l}\text { TTTACATAGCATTTAGCCTTTAGA } \\
\text { TTATGATTTGGGGGTGTTATGGTA }\end{array}$ & $(\mathrm{GT})_{26-1}$ & $50 \mathrm{LP}$ & 14 & 8.94 & 0.980 & 0.891 \\
\hline WPMS05 & $\begin{array}{l}\text { TTCTTTTTCAACTGCCTAACTT } \\
\text { TGATCCAATAACAGACAGAACA }\end{array}$ & $(\mathrm{GT})_{27}$ & $50 \mathrm{LP}$ & 16 & 8.96 & 0.960 & 0.891 \\
\hline WPMS07 & $\begin{array}{l}\text { ACTAAGGAGAATTGTTGACTAC } \\
\text { TATCTGGTTTCCTCTTATGTG }\end{array}$ & $(\mathrm{GT})_{24}$ & $55 \mathrm{LP}$ & 15 & 7.17 & 0.986 & 0.863 \\
\hline WPMS10 & $\begin{array}{l}\text { GATGAGAAACAGTGAATAGTAAAGA } \\
\text { GATTCCCAACAAGCCAAGATAAAA }\end{array}$ & $(\mathrm{GT})_{23}$ & $50 \mathrm{LP}$ & 14 & 6.91 & 0.912 & 0.858 \\
\hline WPMS12 & $\begin{array}{l}\text { TTTTTCGTATTCTTATCTATCC } \\
\text { CACTACTCTGACAAAACCATC }\end{array}$ & $(\mathrm{GT})_{19}$ & $50 \mathrm{NP}$ & 7 & 5.08 & 0.558 & 0.806 \\
\hline WPMS14 & $\begin{array}{l}\text { CAGCCGCAGCCACTGAGAAATC } \\
\text { GCCTGCTGAGAAGACTGCCTTGAC }\end{array}$ & $(\mathrm{CGT})_{28-3}$ & $60 \mathrm{LP}$ & 8 & 4.77 & 0.742 & 0.793 \\
\hline WPMS18 & $\begin{array}{l}\text { CTTCACATAGGACATAGCAGCATC } \\
\text { CACCAGAGTCATCACCAGTTATTG }\end{array}$ & $(\mathrm{GTG})_{13}$ & $60 \mathrm{LP}$ & 5 & 2.04 & 0.408 & 0.511 \\
\hline Mean & & & & 11.3 & 6.27 & 0.792 & 0.802 \\
\hline S.E. mean & & & & 1.686 & 0.940 & 0.087 & 0.051 \\
\hline
\end{tabular}

$N_{\mathrm{a}}$, observed number of alleles per locus; $N_{\mathrm{e}}$, effective number of alleles per locus; $H_{0}$, observed heterozygosity; $H_{\mathrm{e}}$, expected heterozygosity. 
Table 3. - Summary of $F$-statistics and gene flow for all loci.

\begin{tabular}{lllll}
\hline Locus & $F_{\text {IS }}$ & $F_{\text {IT }}$ & $F_{\text {ST }}$ & $N \mathrm{~m}$ \\
\hline WPMS03 & -0.585 & -0.074 & 0.322 & 0.526 \\
WPMS05 & -0.501 & -0.060 & 0.294 & 0.601 \\
WPMS07 & -0.627 & -0.120 & 0.311 & 0.553 \\
WPMS10 & -0.480 & 0.006 & 0.320 & 0.531 \\
WPMS12 & -0.469 & 0.365 & 0.568 & 0.191 \\
WPMS14 & -0.682 & -0.055 & 0.439 & 0.320 \\
WPMS18 & -0.309 & 0.243 & 0.422 & 0.343 \\
Mean & -0.537 & 0.042 & 0.376 & 0.414 \\
S.E.mean & 0.046 & 0.070 & 0.038 & 0.058 \\
\hline
\end{tabular}

$F_{\mathrm{IS}}$, inbreeding coefficient at the population level; $F_{\mathrm{IT}}$, inbreeding coefficient at the total sample level; $F_{\mathrm{ST}}$, proportion of differentiation among populations; $N \mathrm{~m}$, gene flow.

Table 4. - Genetic diversity within population based on microsatellite data.

\begin{tabular}{llllrr}
\hline Population & $N_{\mathrm{a}}$ & $N_{\mathrm{e}}$ & $P(\%)$ & $H_{\mathrm{o}}$ & $H_{\mathrm{e}}$ \\
\hline SHY & 2.00 & 2.00 & 100 & 1.000 & 0.509 \\
$\mathrm{JZ}$ & 2.571 & 1.959 & 100 & 0.857 & 0.485 \\
PW & 4.143 & 2.887 & 100 & 0.556 & 0.556 \\
QHY & 3.857 & 2.708 & 100 & 0.967 & 0.622 \\
LD & 1.571 & 1.571 & 57.1 & 0.571 & 0.291 \\
TS & 4.857 & 3.208 & 100 & 0.672 & 0.608 \\
Mean & 3.167 & 2.389 & 92.9 & 0.771 & 0.512 \\
S.E. mean & 0.534 & 0.260 & 7.15 & 0.080 & 0.050 \\
\hline
\end{tabular}

$N_{\mathrm{a}}$, observed number of alleles per locus; $N_{\mathrm{e}}$, effective number of alleles per locus (KIMURA and CROW, 1964); $P$, percentage of polymorphic loci; $H_{0}$, observed heterozygosity; $H_{\mathrm{e}}$, expected heterozygosity.

over all loci was 6.3 on the basis of the allele frequencies in all tested populations.

A high level of heterozygosity was detected at all loci (Table 2). The observed heterozygosity varied from 0.408 at locus WPMS18 up to 0.986 at WPMS07, the expected heterozygosity varied from 0.511 at locus WPMS18 up to 0.891 at WPMS05, and the mean observed and expected heterozygosities equaled 0.792 and 0.802 , respectively.

\subsection{Genotypic structure and departures from Hardy- Weinberg equilibrium}

WRIGHT's (1978) fixation index $\left(F_{\text {IS }}\right)$ was used to measure the deficiency $\left(F_{\text {IS }}>0\right)$ or excess $\left(F_{\text {IS }}<0\right)$ of heterozygosity. In individual population, the tests for departures from the Hardy-Weinberg equilibrium showed significant deviations at most loci, except in populations TS and PW. In a total of 38 tests, significant departures from the Hardy-Weinberg equilibrium were observed in $76.3 \%$, of the cases primarily due to heterozygote excesses.

$F$ statistics across the six populations for each microsatellite locus are given in Table 3. The overall inbreeding coefficient $F_{\text {IT }}$, with a mean value of 0.042 , showed a slight deficiency of heterozygosity across the whole sample of $P$. cathayana, whereas all loci contained an obvious excess of heterozygosity within population, with a mean $F_{\text {IS }}$ value of -0.537 . All populations of $P$. cathayana indicated strong genetic differentiation among populations, as shown by the $F_{\mathrm{ST}}$ value of 0.376 .

\subsection{Genetic variation within and among populations}

The statistics of genetic diversity within and among populations is presented in Table 4. A high level of genetic variation at the microsatellite loci was observed within populations, with an average of $N_{\mathrm{a}}=3.167$ and of $N_{\mathrm{e}}=2.389$. The percentage of polymorphic loci $(P)$ was $100 \%$ for all sampled population, except for population LD $(57.1 \%)$. The observed heterozygosity $\left(H_{0}\right)$, ranging from 0.556 to 1.000 (average 0.771 ), was clearly higher than the expected heterozygosity $\left(H_{\mathrm{e}}\right)$, ranging from 0.291 to 0.622 (average 0.512 ).

The distribution of the total number of alleles among populations was uneven. Most of the alleles were shared by few populations, whereas a small number of alleles were common to the majority of the populations. NEI's genetic diversity parameters $\left(H_{\mathrm{T}}, H_{\mathrm{S}}, D_{\mathrm{ST}}\right.$ and $\left.G_{\mathrm{ST}}\right)$ are presented in Table 5. The total genetic diversity in the species was very high $\left(H_{\mathrm{T}}=0.799\right)$, and the value of genetic diversity within populations equaled 0.501 $\left(H_{\mathrm{S}}=0.501\right)$. Most of the total genetic diversity was present within populations, and $37.3 \%$ of the total genetic diversity existed among populations $\left(G_{\mathrm{ST}}=0.373\right)$. The hierarchical coefficient $F_{\mathrm{ST}}$ (Table 4 ), estimated according to WRIGHT (1978), ranged from 0.294 to 0.568 with an average of 0.376 , a value very similar to NEI's $G_{\mathrm{ST}}$ value $\left(G_{\mathrm{ST}}=0.373\right)$. It follows that there are high levels of differentiation present among populations of $P$. cathayana. In addition, gene flow (Nm) (Table 4) between pairs of populations is relatively low, ranging 
Table 5. - The total genetic diversity $\left(H_{\mathrm{T}}\right)$, the genetic diversity within populations $\left(H_{\mathrm{S}}\right)$, the genetic diversity among populations $\left(D_{\mathrm{ST}}\right)$ and the proportion of genetic differentiation among populations $\left(G_{\mathrm{ST}}\right)$ (Unbiased measurements, NEI, 1978).

\begin{tabular}{cllll}
\hline Locus & $H_{\mathrm{T}}$ & $H_{\mathrm{S}}$ & $D_{\mathrm{ST}}$ & $G_{\mathrm{ST}}$ \\
\hline WPMS03 & 0.888 & 0.613 & 0.275 & 0.310 \\
WPMS05 & 0.888 & 0.628 & 0.260 & 0.293 \\
WPMS07 & 0.861 & 0.603 & 0.258 & 0.230 \\
WPMS10 & 0.855 & 0.594 & 0.261 & 0.305 \\
WPMS12 & 0.803 & 0.352 & 0.451 & 0.562 \\
WPMS14 & 0.790 & 0.450 & 0.340 & 0.430 \\
WPMS18 & 0.509 & 0.265 & 0.244 & 0.479 \\
Mean & 0.799 & 0.501 & 0.298 & 0.373 \\
S.E. mean & 0.050 & 0.055 & 0.028 & 0.045 \\
\hline
\end{tabular}

Table 6. - NEI's pairwise genetic distances between the six natural populations of $P$. cathayana, based on microsatellite data.

\begin{tabular}{lllllll}
\hline \multicolumn{1}{c}{$D$} & SHY & JZ & PW & QHY & LD & TS \\
\hline SHY & $* * * *$ & & & & & \\
JZ & 0.8304 & $* * * *$ & & & & \\
PW & 0.6794 & 0.6732 & $* * * *$ & & & \\
QHY & 0.8699 & 0.9453 & 0.9177 & $* * * *$ & & \\
LD & 0.8594 & 0.6642 & 0.7079 & 0.43875 & $* * * *$ & \\
TS & 0.6562 & 0.5023 & 0.3487 & 0.47625 & 0.4631 & $* * * *$ \\
\hline
\end{tabular}

from 0.191 to 0.601 , with the mean value equaling 0.414 .

\subsection{Populations genetic relationships}

The extent of divergence between populations was determined by calculating genetic distances $(D)$ (Table 6 ). For population pairs, the genetic distances $(D)$ ranged from 0.3487 to 0.9453 with the mean value equaling 0.6688. A UPGMA dendrogram, based on the genetic distances, was constructed to graphically visualize the genetic relationships among the populations (Fig. 2). The six populations were separated into three major groups: the first group consisted of populations TS, PW and JZ, the second group consisted of populations QHY and LD, while population SHY was distinct from the others and clustered alone as a separate group.

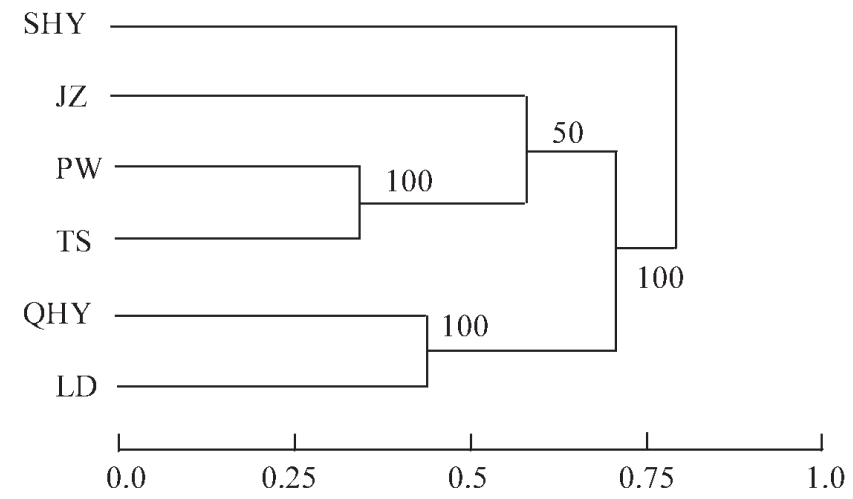

Figure 2. - Dendrogram of the genetic relationships between the six natural populations of $P$. cathayana, including bootstrap support values.

\section{Discussion}

In the southeastern part of the Qinghai-Tibetan Plateau of China, the abundant genetic resources of Populus are mainly attributable to specific geological and ecological factors present in the region and to the biological properties of the genus. As a part of the Qinghai-Tibetan Plateau, the intersecting mountains were formed during the geological period when the QinghaiTibetan ground gradually rose and collided between the Qinghai-Tibetan continent and the Sichuan and Huadong continent. The intersecting mountains, running from south to north, provided a superior shelter for plants during the fourth ice age. Therefore, abundant species, including many presently rare and endangered species have been preserved in this region. During the long evolutionary process, changes in distributions and adaptations to the harsh conditions have taken place (YU et al., 2003; WANG et al., 2005). Previous studies have showed that geographical isolation, complex and variable climate conditions are the main factors contributing to the genetic composition of plant populations (GEHRING and LinHART, 1992; STRAUs et al., 1992; YeH et al., 1995). The populations of $P$. cathayana occur in disjunctive mountain areas with a large geographic range of vertical altitude. Consequently, the species has been exposed to a range of conditions, which have influenced the pattern of genetic diversity.

In this study, seven microsatellite loci were investigated in samples of $P$. cathayana representing six populations occurring in the Qinghai-Tibetan Plateau of China. A total of 79 alleles were identified (a mean of 11.3 alleles per locus), and the mean expected heterozygosity was found to equal 0.802 . These results show that the 
level of genetic diversity present in the populations of $P$. cathayana is high. The genetic diversity detected in our study based on the use of microsatellite markers is significantly higher than that previously observed in the genus Populus, based on allozyme markers (RAJORA et al., 1991; LUND et al., 1992; STEVEN et al., 1992; LEGIONNET and LEFÈVRE, 1996), and on RAPD and AFLP markers (WINFIELD et al., 1998; RAJORA and RAHMAN, 2003).

The spatial and temporal distribution of alleles and genotypes forms the genetic structure of a population (LOVELESS and HAMRICK, 1984). In the present study, the Hardy-Weinberg exact tests conducted for all loci and populations revealed significant heterozygosity excesses. Such excesses of heterozygosity within populations might be the result of a high level of outbreeding and extensive population mixing at the local scale. The level of genetic differentiation among populations $\left(G_{\mathrm{ST}}=0.373\right)$ was much higher than that of most other forest tree species investigated using SSR markers (e.g., MAGUIRE et al., 2002; WANG et al., 2005), or that of the genus Populus based on isozyme (AGNES and FRANCOIS, 1996) and SSR markers (IMBERT and LEFÈVRE, 2003), but equal to that detected in $P$. cathayana based on RAPD markers (Li et al., 1997).

Considering the strong vegetative reproduction ability of poplars, it is important to avoid sampling the same ramets. Therefore, the individual cuttings sampled from a population should be separated by a distance great enough. However, because of strong agamogenesis of the root and branch, the Populus species can quickly spread after natural or human disturbances, and form clones of the same genotype. Especially in such cases, there is a high risk to collect cuttings belonging to the same clone. In general, clonal propagation may lead to a lower level of genetic diversity within populations and a higher level of genetic differentiation between populations. When planning an appropriate sampling protocol within populations and species, different factors, including biological features, geographical distribution, breeding system and environmental heterogeneity of the species, should be considered. In future population genetic studies on Populus species, which have considerable clonal capacity, distances between within-population samples should be as large as possible, and the total investigation should include populations representing different environmental conditions.

The high level of differentiation among populations is usually thought to result from limited gene flow. Since poplars are dioecious, wind-pollinated plants, with light pollen and small cotton-tufted seeds easily dispersed by wind and water, the gene flow is expected to be high. However, in our study the level of gene flow was found to be very low $(N \mathrm{~m}=0.414)$. This can be attributed to large geographical distances and complex terrain with physical obstacles, present in the region of the southeastern part of Qinghai-Tibetan Plateau, which can block gene flow even in a species with generally good dispersal ability. In addition, the variable climatic conditions of the region influence the flower phenology, consequently, limit pollen exchange among the populations.

The great genetic distances detected (mean $\mathrm{D}=0.6688$ ) and the results of the cluster analysis show that there is a clear genetic separation among the populations. Generally, the populations from the same region are grouped together and form a cluster. Populations TS and PW, which are located on the brim of the eastern zone of the Qinghai-Tibetan Plateau with a humid monsoon climate, clustered together, and population JZ, originating from the northern part of the Mingshan Mountains with differing ecological and geographic parameters clustered with populations TS and PW. The second group included populations $\mathrm{LD}$ and $\mathrm{QHY}$, which are located in the plateau regions of the northeastern Qinghai province and grow under dry and cold plateau climate. Population SHY, which occurs on the southern brim of the Qinghai-Tibetan Plateau, formed a separate cluster. Therefore, genetic relationships among populations are not strictly associated with the geographical location, but they relate also to the climate conditions of the region.

During recent years, population SHY has been considered by some taxonomists to be a new species. The results of the present population genetic study also confirm this idea. We suggest that the population SHY should be regarded as an ecologically divergent species of $P$. cathayana. and that the allopatric speciation event has been promoted by a low level of gene flow between natural populations of $P$. cathayana.

\section{Acknowledgements}

The research was supported by the Program of "100 Distinguished Young Scientists" and "Knowledge Innovation Engineering" of the Chinese Academy of Sciences (No. KSCX2-SW-115), and the Academy of Finland (No. 206577).

\section{References}

AGNES, L. and L. Francois (1996): Genetic variation of the riparian pioneer tree species Populus nigra L. I. Study of population structure based on isozymes. Heredity 77: 629-637.

AHUJA, M. R. (2001): Recent advances in molecular genetics of forest trees. Euphytica 121: 173-195.

BECKMANN, J. S. and M. Soller (1990): Toward a unified approach to genetic mapping of eukaryotes based on sequence tagged microsatellite. Bio/Technology 8: 930-932.

Castiglione, S., G. Wang, G. Damiani, C. Bandi, S. BisofFI and F. SALA (1993): RAPD fingerprints for identification and for taxonomic studies of elite poplar (Populus spp) clones. Theor. Appl. Genet. 87: 54-59.

DaYAMANDAN, S., O. P. RAJORA and K. S. BAWA (1998): Isolation and characterization of microsatellites in trembling aspen (Populus tremuloides). Theor. Appl. Genet. 96: 950-960.

Echt, C. S., P. M. Marquardt, M. Hseih and R. ZahoRCHAK (1996): Characterization of microsatellite markers in eastern white pine. Genome 39: 1102-1108.

Felsenstein, J. (2004): PHYLIP (Phylogeny Inference Package), Version 3.6. Department of Genome Sciences and Department of Biology, University of Washington, Seattle.

GaO, J. S., Y. Y. LiU, Y. Q. FU, J. FU, J. WanG and Z. X. YANG (2004): On growth character of young trees of Populus cathayana of different provenances. Journal of Zhejiang Forestry College 21: 115-118. 
Gehring, J. L. and Y. B. LinharT (1992): Population structure and genetic differentiation in native and introduced populations of Descha mpsia Caespuosa (poaceae) in the Colorado alpine. Am. J. Bot. 79: 1337-1343.

IMBERT, E. and F. LEFÈVRE (2003): Dispersal and gene flow of Populus nigra (Salicaceae) along a dynamic river system. J. Ecol. 91: 447-456.

LEGIONNET, A. and F. LEFÈVRE (1996): Genetic variation of the riparian pioneer tree species Populus nigra L. I. Study of population structure based on isozymes. Heredity 77: 629-637.

Li, K. Y., M. R. Huang, Z. X. YANG, M. X. Wang and F. H. HuANG (1997): Genetic differentiation of Populus cathayana. Acta Botanica Sinica 39: 753-758.

LOVELESS, M. D. and J. L. HAMRICK (1984): Ecological determinants of genetic structure in plant populations. Annu. Rev. Ecol. Syst. 15: 65-96.

Lund, S. T., G. R. Furnier and C. A. Mohn (1992): Isozyme variation in quaking aspen in Minneasota. Can. J. For. Res. 22: 521-524.

Maguire, T. L., R. Peakall and P. Saenger (2002): Comparative analysis of genetic diversity in the mangrove species Avicenn iamarina (Forsk.) Vierh. (Avicenniaceae) detected by AFLPs and SSRs. Theor. Appl. Genet. 104: 388-398.

Maniatis, T., E. F. Fritisch and J. SAmbrook (1982): Molecular Cloning. Cold Spring Harbor Laboratory Press, Cold spring Harbor, New York.

NEI, M. (1978): Estimation of average heterozygosity and genetic distance from a small number of individuals. Genetics 89: 583-590.

RAHMAN, M. H. and O. P. RAJORA (2002): Microsatellite DNA fingerprinting, differentiation, and genetic relationships of clones, cultivars, and varieties of six poplar species from three sections of the genus Populus. Genome 45: 1083-1094.

RAHMAN, M. H., S. DAYANANDAN and O. P. RAJORA (2000): Microsatellite DNA markers in Populus tremuloides. Genome 43: 293-297.

RAJORA, O. P., L. Zsuffa and B. P. DANCIK (1991): Allozyme and leaf morphological variation of eastern cottonwood at the northern limits of its range in Ontario. For. Sci. 37: 688-702.

RAJORA, O. P. and M. H. RAHMAN (2003): Microsatellite DNA and RAPD fingerprinting, identification and genetic relationships of hybrid poplar (Populus $\mathrm{x}$ canadensis) cultivars. Theor. Appl. Genet. 106: 470-477.

Smith, D. N. and M. E. Devey (1994): Occurrence and inheritance of microsatellite loci in Pinus radiata. Genome 37: 977-983.
Smulders, M., J. VAn Der Schoot, P. Arens and B. VosMAN (2001): Trinucleotide repeat microsatellite markers for black poplar (Populus nigra L.). Molecular Ecology Notes 1: 188-190.

Steven, T. L., G. R. Furnier and C. A. Mohn (1992): Isozyme variation in quaking aspen in Minnesota. Can. J. For. Res. 22: 521-524.

Straus, S. H., J. Bousquet and K. Hipkins (1992): Biochemical and molecular genetic markers in biosystemtic studies of forest trees. New For. 6: 125-158.

Su, X. H., Q. W. Zhang, X. W. Zheng and X. H. Zhang (1998): Construction of Populus deltiodes Marsh X P. cathayana Rehd. molecular linkage map. Scientia Silvae Sinicae 34: 29-37.

TABbener, H. E. and J. E. CotTrell (2003): The use of PCR based DNA markers to study the paternity of poplar seedlings. For. Ecol. Manage. 179: 363-376.

VAN Der Schoot, J., M. Pospikova, B. Vosman and M. J. M. SMULDERS (2000): Development and characterization of microsatellite markers in Black Poplar (Populus nigra L.). Theor. Appl. Genet. 101: 317-322.

Wang, Y. H., J. X. Luo, X. M. Xue, H. KorPelainend and C. Y. LI (2005): Diversity of microsatellite markers in the populations of Picea asperata originating from the mountains of China. Plant Sci. 168: 707-714.

WEISGERBER, H. and Y. HAN (2001): Diversity and breeding potential of poplar species in China. Forestry Chronicle 77: 227-237.

Winfield, M. O., G. M. Arnold and F. Cooper (1998): A study of genetic diversity in Populus nigra subsp. betulifolia in the Upper Severn Area of the UK using AFLP markers. Mol. Ecol. 7: 3-10.

Workman, P. L. and J. D. Niswander (1970): Population studies on southwestern Indian tribes. II. Local genetic differentiation in the Papago. Am. J. Hum. Genet. 22: 24-49.

WRIGHT, S. (1978): Evolution and the genetics of populations, vol 4. Variability winthin and among natural populations. University of Chicago Press, Chicago.

YANG, Z. X., S. Z. WANG and Y. L. HAN (1996): Cold tolerance variation of Populus cathayana clones from different populations. Forest Research 9: 475-480.

YeH, F. C., D. K. CHONG and R. C. YANG (1995): RAPD variation within and among natural populations of trembling aspen (Populus tremuloid Michx) from Alberta. J. Heredity 86: 454-459.

YU, S. Q., J. LIU, D. R. FU, D. J. LIU and Y. Q. LIU (2003): Characteristics of Tacamachaca genes in the western Sichuan plateau. Journal of Zhengjiang Forestry College 20: 27-31. 